\title{
WDM cross-connect cascade based on all-optical wavelength converters for routing and wavelength slot interchanging using a reduced number of internal wavelengths
}

Pedersen, Rune Johan Skullerud; Mikkelsen, Benny; Jørgensen, Bo Foged; Nissov, Morten; Stubkjær, Kristian; Wunstel, K; Daub, K.; Lach, E; Laube, G; Idler, W

Total number of authors:

13

Published in:

Technical Digest of the Optical Fiber Communication Conference and Exhibit

Link to article, DOI:

10.1109/OFC.1998.657203

Publication date:

1998

Document Version

Publisher's PDF, also known as Version of record

Link back to DTU Orbit

Citation (APA):

Pedersen, R. J. S., Mikkelsen, B., Jørgensen, B. F., Nissov, M., Stubkjær, K., Wunstel, K., Daub, K., Lach, E., Laube, G., Idler, W., Schilling, M., Doussiere, P., \& Pommerau, F. (1998). WDM cross-connect cascade based on all-optical wavelength converters for routing and wavelength slot interchanging using a reduced number of internal wavelengths. In Technical Digest of the Optical Fiber Communication Conference and Exhibit (pp. 5859). IEEE. https://doi.org/10.1109/OFC.1998.657203

\section{General rights}

Copyright and moral rights for the publications made accessible in the public portal are retained by the authors and/or other copyright owners and it is a condition of accessing publications that users recognise and abide by the legal requirements associated with these rights.

- Users may download and print one copy of any publication from the public portal for the purpose of private study or research.

- You may not further distribute the material or use it for any profit-making activity or commercial gain

- You may freely distribute the URL identifying the publication in the public portal 
A fiber cross-connect (FXC) accepts multiwavelength signals and cross-connects them as multiwavelength signal bundles without demultiplexing the multiwavelength signals into their constituent single wavelength signals. It also accepts single wavelength signals and cross-connects them as single wavelength signals. A wavelength selective cross-connect (WSXC) accepts multiwavelength signals and supports constituent single wavelength signal cross-connections. A wavelength interchange cross-connect (WIXC) includes the wavelength interchange function. Architecture functional entities of add-drop multiplexers and cross-connects include multiwavelength transport interfaces, single wavelength client layer interfaces, switch fabric, optical signal monitoring, optical interconnects, and network control and management interface.

The WSXC demonstrated in the MONET Cross-Connect testbed provides cross-connect functionality between four input and output fibers each carrying a bundle of up to eight multiplexed single wavelength signals. It contains thirteen circuit packs residing in a single bay and optically interconnected by a single-mode optical backplane. The system has six types of circuit packs namely, input transport interface, output transport interface, input client interface, output client interface, switch, and monitor and alarm. The input transport interface provides signals on a given fiber enough amplification to compensate for losses incurred in traveling from the upstream network element and for losses incurred within the system. This is accomplished by using two-stage erbiumdoped fiber amplifiers (EDFAs). In addition, it demultiplexes the multiwavelength signal into eight constituent single wavelength signals. Signal conditioning and cross-connections are done on the switch pack using variable optical attenuators and guided wave optical switches. The output transport interface multiplexes eight single wavelength signals into a multiwavelength signal and provides enough amplification for the multiwavelength signal to compensate for the outside plant loss.

The input client interface allows up to eight single wavelength signals to be added and the output client interface allows up to eight single wavelength signals to be dropped. In addition to being configured as a WSXC with four transport interfaces and no add/drop, the same system can also be configured as a WSXC with three transport interfaces and one client interface to facilitate add/drop of up to eight single wavelength signals, or as a two fiber WADM with two transport interfaces and two client interfaces to allow adding and dropping of up to sixteen single wavelength signals.

The system visual alarms reside on the monitor and alarm pack. The data from all monitoring points within the system is routed to the monitor and alarm pack and the system controller. For the purposes of signal monitoring, failure detection and isolation, optical power taps are strategically located within the system. The optical signal that is tapped is routed to one of two monitoring mechanisms. The first of these mechanisms, performance monitoring ( $\mathrm{PM})$, measures signal power. It is used to detect fiber cuts within the system, and between an upstream network element and the appropriate input transport interface. The second monitoring mechanism, enhanced performance monitoring (EPM), is used to provide detailed signal characteristics of the signals such as signal-tonoise ratio and wavelength registration. The data from various monitoring points is used by the system controller to generate alarm and status information and is made available to network control and management system via a TCP/IP link over ATM on OC-3c.

Optical switches used to implement these optical cross-connects must exhibit low loss, low cross talk, broad optical bandwidth, polarization-independent operation, uniform performance, and allow the system to be grow- able. The required technologies that are currently in early stages of development are those for wavelength interchange, and developments in this area could strongly influence the design of optical cross-connects. The purpose of this paper is to review the wavelength add-drop multiplexer and crossconnect systems from architecture and design considerations perspective.

TuJ2

2:30pm

WDM cross-connect cascade based on all-optical wavelength converters for routing and wavelength slot interchanging using a reduced number of internal wavelengths

R.J.S. Pedersen, B. Mikkelsen, B.F. Jørgensen, M. Nissov, K.E. Stubkjaer, K. Wünstel,* K. Daub,* E. Lach,* G. Laube,* W. Idler,* M. Schilling,* P. Doussiere,** F. Pommerau,** Center for Broadband Telecommunications, Dept. of Electromagnetic Systems, Technical University of Denmark, Bldg. 348, DK-2800 Lyngby, Denmark

Optical transport layers need rearrangeable wavelength-division multiplexing optical cross-connects (OXCs) to increase the capacity and flexibility of the network. ${ }^{1}$ It has previously been shown that a cross-connect based on all-optical wavelength converters for routing as well as wavelength slot interchanging ${ }^{2,3}$ can be used to create a robust and nonblocking $\mathrm{OXC}$. However, for an $\mathrm{OXC}$ with $n$ fiber inlets each carrying $m$ wavelengths the OXC requires $n \times m$ internal wavelengths, which constrains the size of the cross-connect.

In this paper we therefore propose and demonstrate an architecture that uses a reduced set of internal wavelengths without sacrificing crossconnecting capabilities. By inserting a partly equipped $\mathrm{OXC}$ with the new architecture in a 10-Gbit/s re-circulating loop setup we demonstrate the possibility of cascading up to ten OXCs. Furthermore, we investigate the regenerating effect of the $\mathrm{OXC}$ on signals that suffers from interferometric cross talk.

The proposed architecture of the non-blocking $\mathrm{OXC}$ is shown in Fig. 1. The architecture allows any OXC size but is for simplicity shown for a $3 \times 3$ OXC with four wavelengths. The OXC can be divided into a number of blocks equal to the number of external wavelengths. Each block then performs a channel selection followed by a wavelength con-

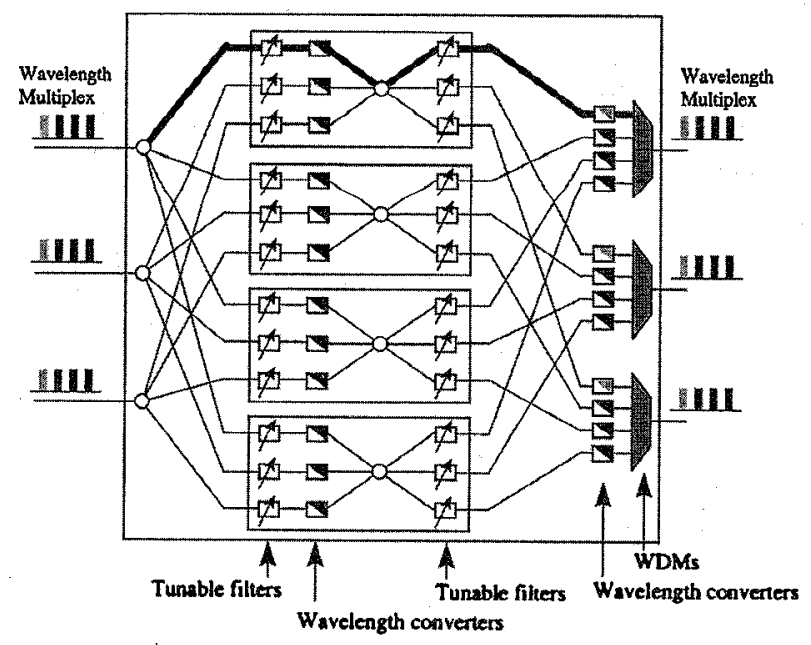

TuJ2 Fig. 1. Architecture of the WDM cross-connect. 

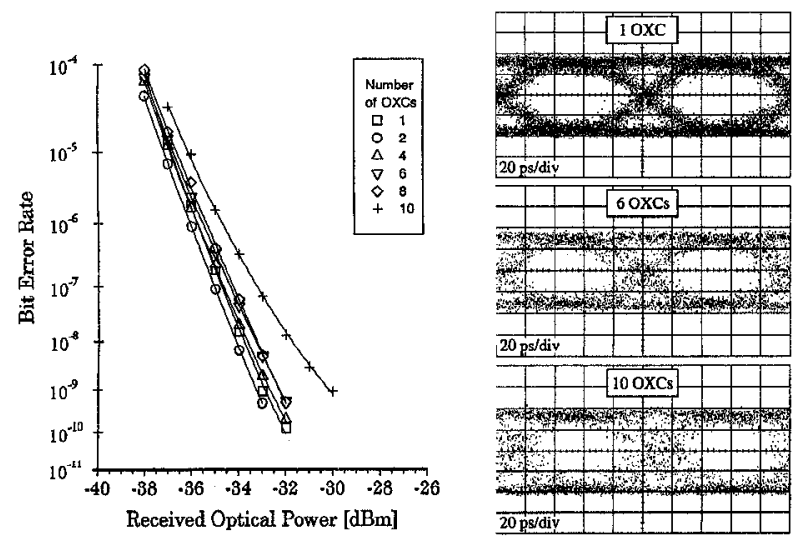

Tuj2 Fig. 2. BER curves for a cascade of $1,2,4,6,8$, and 10 OXCs and eye diagrams for a cascade of 1,6 , and 10 OXCs.

version to an internal set of wavelengths as well as a second broadcast and select function. The number of internal wavelengths equals the number of fiber inlets to the OXC. As in Refs. 2 and 3 the wavelength slot interchange is performed by an output wavelength converter before multiplexing to the fiber outlets of the OXC.

A partly equipped OXC is implemented for experimental demonstration (thick line in Fig. 1). The filters used are tunable bandpass filters with a bandwidth of 1.3-1.5 $\mathrm{nm}$. The first wavelength converter is based on cross-gain modulation in a polarization-insensitive semiconductor optical amplifier (SOA). The output wavelength conversion is performed by an interferometric wavelength converter (SOAs monolithically integrated in a Michelson interferometer). This combination of wavelength converters has previously proven advantageous in terms of a large input power dynamic range and a good output signal quality. ${ }^{2,3}$

The two star couplers are represented by equivalent losses of 10 and $8 \mathrm{~dB}$. This setup would accommodate a $4 \times 4$ OXC with eight wavelengths on each fiber inlet. The output multiplexer is an arrayed waveguide multiplexer with an insertion loss of $\sim 7 \mathrm{~dB}$.

The experimental demonstration is performed using a $10-\mathrm{Gbit} / \mathrm{s}$ recirculating loop setup. ${ }^{4}$ Figure 2 shows the measured bit-error-rate (BER) curves for a cascade of $1,2,4,6,8$ and 10 OXCs. The variation of receiver sensitivity (@ BER $=10^{-9}$ ) is within $1 \mathrm{~dB}$ for cascades up to eight OXCs

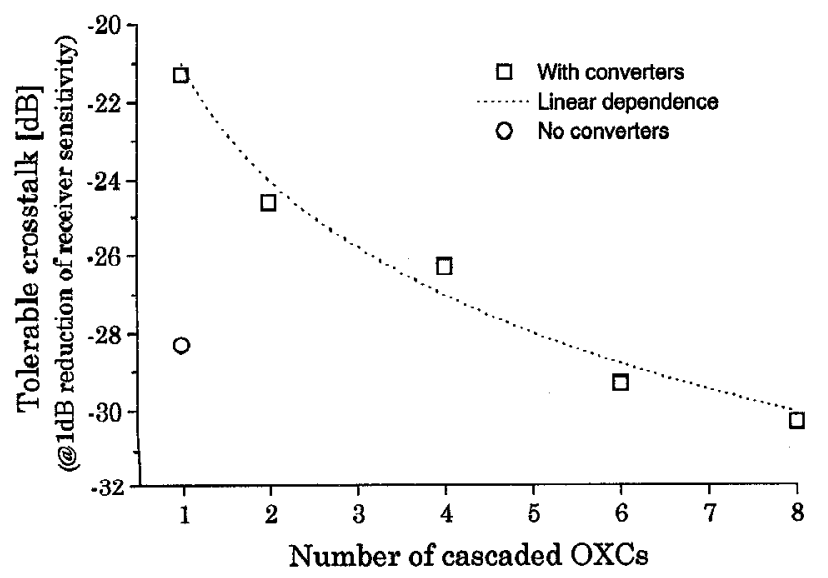

Tuj2 Fig. 3. Level of interference cross talk per round trip that can be tolerated for a receiver sensitivity reduction of $1 \mathrm{~dB}$ as a function of round trips in the loop setup. Dashed line corresponds to a power summation of cross talk contributions. whereas the receiver sensitivity is reduced by $2 \mathrm{~dB}$ when increasing the cascade of OXCs from eight to ten. Also shown in Fig. 2 are eye diagrams for cascades of 1,6 , and 10 OXCs indicating that timing jitter accumulates.

Influence of interference cross talk is measured by adding cross talk to the signal entering the $\mathrm{OXC}$, thereby simulating cross talk from add/drop elements between OXCs. The level of cross talk that causes a receiver sensitivity reduction of $1 \mathrm{~dB}$ is shown in Fig. 3. Also shown is a measurement for one round trip without the wavelength converters. This result shows that up to five OXCs with wavelength converters can tolerate the same level of cross talk as one OXC without converters.

We have presented an OXC architecture based on all-optical wavelength converters for routing and wavelength slot interchange that only requires a number of internal wavelengths equal to the number of fiber inlets to the OXC. It is demonstrated that the OXC can be cascaded and features an increased tolerance to interference cross talk.

* Alcatel Telecom Research Division, Stuttgart, Germany

**Alcatel Alsthom Recherche, Marcoussis, France

1. G.R. Hill et al., IEEE J. Lightwave Technol. 11, 667-679 (1993).

2. R.J.S. Pedersen et al., accepted for publication in Electron. Lett.

3. B. Mikkelsen et al., in Proceedings of European Conference on Optical Communication (ECOC'97), 1997, paper TU4A-2.

4. M. Nissov et al., in Optical Fiber Communication Conference, Vol. 6 of 1997 OSA Technical Digest Series (Optical Society of America, Washington, D.C., 1997), pp. 49-50.

5. B. Mikkelsen et al, in Optical Fiber Communication Conference, Vol. 6 of 1997 OSA Technical Digest Series (Optical Society of America, Washington, D.C., 1997), pp. 124-125.

TuJ3

2:45pm Reduced parametric wavelength-interchanging cross-
connect architectures with scalability and modularity

\section{S.J.B. Yoo, Bellcore, 331 Newman Springs Road, Red Bank, New Jersey 07701}

Wavelength conversion in wavelength-division multiplexing (WDM) networks offers distributed network management and reduction in blocking rising from wavelength contentions. ${ }^{1}$ While it is generally accepted that the benefit of wavelength conversion rises with increased traffic load, the main argument against wavelength conversion has been the cost and the complexity associated with realizing it in the network. Such a realization requires deployment of wavelength-interchanging cross-connects (WIXCs), which is far more sophisticated than wavelength-selective cross-connects (WSXCs), which provide only space switching based on wavelengths. Hence, it is preferred that WSXCs are deployed first and, if the blocking rate rises, they are upgraded to WIXCs in a modular manner. Another consideration for future upgrades is scalability both in the number of space ports and in the number of wavelength channels. Rising traffic demand in the network may continue to drive the need for an increased number of wavelength channels. Unfortunately, the existing WIXC architectures based on variable-input-tofixed-output wavelength converters do not offer such scalability or modularity for upgrades. This paper examines and demonstrates the case for scalable upgrades of WIXCs based on parametric wavelength converters. We discuss the capability of upgrading a WSXC to a partially blocking WIXC, and eventually to a rearrangeably nonblocking WIXC by incrementally adding appropriate modules.

Parametric wavelength conversion based on difference-frequency generation ${ }^{2}$ offers simultaneous multichannel conversion with a mirror image mapping property. Figure 1 illustrates this mapping property. The 